ISSN: 0210-7287

DOI: https://doi.org/10.14201/161620201091104

\title{
MADRE! DE DARREN ARONOFSKY (2017): UN POEMA CINEMATOGRÁFICO
}

\author{
Mother! by Darren Aronofsky (2017): \\ A Cinematographic Poem
}

José SEOANE RIVEIRA

Universidad de Salamanca

seoaneriveira@usal.es

Recibido: marzo de 2020; Aceptado: mayo de 2020; Publicado: diciembre de 2020 Ref. Bibl. JOSÉ SEOANE RIVEIRA. MADRE! DE DARREN ARONOFSKY (2017): UN POEMA CINEMATOGRÁFICO. 1616: Anuario de Literatura Comparada, 10 (2020), 91-104

RESUMEN: El artículo analiza el filme Madre!, de Darren Aronofsky, una obra cuya recepción por parte de crítica y público fue polémica debido a su extraño argumento y sus formas aparentemente caóticas que mezclan narrativa cinematográfica clásica y procedimientos más cercanos al cine poético. A lo largo de estas páginas se establece una hipótesis que otorga, a partir del análisis del filme, un sentido a la obra y que propone una lectura crítica totalmente diferenciada de las que se han venido haciendo hasta el momento. La hibridación y las tensiones entre las narrativas clásicas cinematográficas y los procedimientos formales antinarrativos hacen de Madre! una pieza fundamental para entender las relaciones entre el cine contemporáneo y la poesía.

Palabras clave: cine; poesía; cine poético; Darren Aronofsky; Madre!; metatextualidad. 
ABSTRACT: The article analyzes the film Mother!, by Darren Aronofsky, a work whose reception by critics and audiences was controversial due to its strange argument and its seemingly chaotic forms that mix classical cinematographic narrative and procedures that are closer to poetic cinema. Throughout these pages a hypothesis is established that grants, from the analysis of the film, a meaning to the film and that proposes a critical reading totally differentiated from those that have been done so far. Hybridization and tensions between classic cinematographic narratives and formal anti-narrative procedures make Mother! a fundamental piece to understand the relationships between contemporary cinema and poetry.

Keywords: Film; Poetry; Poetic Cinema; Darren Aronofsky; Mother!; Metatextuality.

\section{PRELIMINAR}

El estreno de Madre!, el séptimo largometraje del director estadounidense Darren Aronofsky en 2017 (con Javier Bardem, Jennifer Lawrence, Ed Harris y Michelle Pfeiffer como cuarteto protagonista), se recibió con una expectación inusitada entre los espectadores de todo el mundo. Esta circunstancia, habitual en algunas producciones de cineastas que conciben sus obras como objetos artísticos pero que ocasionalmente quieren (o necesitan) seducir a una gran cantidad de público $^{1}$, marcó en gran medida las expectativas del público que acudió a las salas. Lo mismo ocurrió con la crítica especializada, cuyas reseñas y análisis no reflejaron más interés que el que proporciona una experiencia cinematográfica de intensidad inusitada; si bien en los Estados Unidos el filme fue recibido con rechazo más que con alegría (Aronofsky fue nominado como director a los premios Razzie de 2018), en España los críticos se posicionaron tanto a favor como en contra del experimento estético, y algunos centraron sus esfuerzos en descubrir el significado de la película ${ }^{2}$. Varias de las frases que la crítica española dedicó a la obra de Aronofsky fueron: "El director juega a componer y destruir símbolos de una forma anárquica, provocadora y visceral" (Martínez 2017); "La anarquía se apodera de la pantalla» (Koch 2017); "Virtuoso ejercicio de pura forma cinematográfica [...] el relato y

1. Véanse, por ejemplo, los casos de M. Night Shyamalan (El bosque, 2004), Paul Thomas Anderson (The Master, 2012), Terrence Malick (El árbol de la vida, 2011) o Michael Haneke (Funny Games, 2007).

2. Véase, como ejemplo, el artículo que Mireia Mullor dedicó en Fotogramas a la búsqueda de un sentido simbólico a la historia del filme y a sus personajes: «Esto es lo que de verdad significa Madre! de Darren Aronofsky». 
su dimensión simbólica [...] está orientado a proporcionar al espectador una experiencia subjetiva» (Costa 2017); "La ilógica de la trama produce ciertas ganas de reír» (Rodríguez Marchante 2017); «Una película de historia endeble e irracional» (Llopart 2017); "Lo que sobre todo importa [...] no son los significados que encierra sino la contundencia con la que sacude emocional y físicamente (Salvá 2017)"; "Colección de burdas y surrealistas metáforas sobre el desconcierto del mundo contemporáneo» (Yáñez 2017); "Admite tantas interpretaciones como espectadores" (Loureda 2017).

Existe, pues, una cierta correlación entre las reseñas, sean estas positivas o negativas: la irracionalidad de la trama, la exuberancia de su presentación formal y la aparente codificación simbólica de su significado se presentan como los tres pilares sobre los que los espectadores de Madre! deben construir su experiencia cinematográfica. Está claro que, a pesar de la presencia de actores de reconocidísima fama para el público medio, el filme no está elaborado según las pautas del cine comercial al que ese mismo público está acostumbrado, y que siguen atadas a las formas narrativas más básicas del cine clásico estadounidense de mediados del siglo XX.

El argumento de Madre! presenta a un poeta sin nombre, al que siempre se llama "Él», interpretado por Javier Bardem y que vive en una casa aislada, en medio del bosque, con su esposa, también sin nombre, llamada "Ella» e interpretada por Jennifer Lawrence. El poeta está atravesando una crisis creativa y su esposa, quien se dedica principalmente a las tareas del hogar, intenta ayudarle a crear un ambiente propicio para la escritura. De pronto, un cirujano, interpretado por Ed Harris, sacude la cotidianidad del matrimonio pues llega a la casa aparentemente perdido en busca de refugio para una noche; poco después, su mujer, interpretada por Michelle Pfeiffer, se instala también en la casa y con este cuarteto de personajes empiezan a producirse una serie de sucesos que irán destruyendo, primero lentamente y después a toda velocidad, la estabilidad emocional del matrimonio y su propio hogar.

Hasta aquí, todo lo que se puede relatar de la trama, pues no estamos ante una película convencional sino ante otra cosa; no es convencional su historia, ni lo son sus formas, ni lo es su sentido. Como el título de este artículo indica, es necesario pensar Madre! desde las coordenadas de la poesía porque Madre! es un poema cinematográfico, y a su exposición y clarificación dedicaremos las páginas siguientes.

\section{PRIMER ACTO: LA NARRATIVA POÉTICA}

Dante comienza la Divina comedia con los archiconocidos versos "A la mitad del viaje de nuestra vida me encontré en una selva oscura, por 
haberme apartado del camino rectom; Milton, su Paraíso perdido invocando a una instancia narradora superior, "Canta musa celestial, la primera desobediencia del hombre y el fruto del árbol prohibido»; Poe, El cuervo: «Una vez, en la lúgubre media noche, mientras meditaba débil y fatigado....; y Eliot, la Tierra baldía con el premonitorio "Abril es el mes más cruel».

El poema cinematográfico de Aronofsky comienza del mismo modo que los anteriores poemas narrativos, esto es: presentando primero el cronotopo en el que sitúa su historia e introduciendo al personaje principal: Ella. Lo primero y más importante que el espectador debe reconocer en Madre! es que el filme es la versión visual del poema que escribe Él, el poeta, en la historia; estamos, por tanto, ante un caso de remedialidad, que según Pardo y Gil (2018, 20-25) se da cuando «un medio principal acoge en su seno la presencia de otro", y más concretamente en lo que se debe denominar "metamediación", pues Madre! es, en sí misma, una obra (películapoema) que reduplica otra (poema que escribe el poeta) con su propio lenguaje (imagen en movimiento) y la comenta y reflexiona sobre ella y su proceso creativo. Una prueba inequívoca de que el filme se trata del poema que escribe Él es el comienzo: tras caer una lágrima de lo que se adivina el ojo de una mujer quemada, el poeta coge un diamante y, a través de este objeto, se va generando la imagen de la casa desde las tinieblas; es sencillo, pues, reconocer la metáfora por la cual el vate recibe la inspiración poética y se da comienzo a la narración.

Los primeros planos de la película (los primeros versos del poema, pues, imaginemos) están dedicados a describir, primero frontalmente, después desde un lateral y finalmente desde atrás a su protagonista, Ella, la mujer, que sirve también de musa del poeta como veremos más adelante. La cámara la sigue por la casa y el director aprovecha su deambular para describir los escenarios y las habitaciones; el plano principal del operador es desde el hombro, con el ligero temblor que ello provoca y la consiguiente sensación de subjetividad en el espectador que genera: es preciso traer a colación, aquí, a Pasolini (1970, 24-33) y su escrito teórico que asocia el cine de poesía con el estilo indirecto libre literario en general, y el estilo indirecto libre cinematográfico con el uso de la cámara manual y la apelación a la subjetividad. Aronofsky está utilizando una gramática visual que proviene de los cines modernos, cuyas renovaciones estéticas en el medio siglo buscaban aproximar el arte fílmico más hacia el poema, si hacemos la comparación literaria, que hacia la novela a la que se asimilaban hasta entonces sus formas clásicas (Pérez Bowie 2008, 58).

La casa, pues, desnuda, se nos presenta vacía y amplia, con techos altos y largas tarimas, con ventanales diáfanos y la capacidad de albergar en ella a nuestros protagonistas y su historia. Ella sale, entonces, al porche y 
observa el jardín, cuyas características lo sitúan fuera de cualquier tiempo o lugar reconocibles pues se nos muestra como un bosque indeterminado, lleno de arbustos y árboles que no permiten ver más allá de unas decenas de metros: la indefinición del cronotopo acentúa el cariz poemático de la narración, como señala Bazin (1990, 188). Es entonces cuando Él, el poeta, aparece, y lo hace primero a nivel verbal y solo después a nivel visual; en la doble articulación del relato fílmico se da prioridad a la sonoridad de la voz poética y se presenta así el "yo poético" del poeta/director, mediante la potenciación de las cualidades rítmicas y evocadoras de una voz profunda, modulada y abrupta, en este caso, como la que es capaz de proyectar Javier Bardem 3 . A diferencia de Ella, que es descrita claramente en el filme-poema, Él no lo es y su aparición es repentina y por medio de la voz: estamos, por un lado, ante un personaje de la narración poética y, por el otro, ante la presencia del poeta, cuyo primer acto es la palabra.

La protagonista es entonces mostrada en el poema como sujeto inspirador, como musa, de forma muy clara en la narración: Ella pinta un brochazo en una pared blanca y la cámara atraviesa la mancha para mostrar lo que es el embrión, el corazón del poema ya mostrado en la apertura del filme; ahora se "narrativiza» esa metáfora visual, es decir, se introduce en el nivel de la historia y el poeta/director describe a través de la acción de su personaje femenino el propio procedimiento creativo de la película/poema.

La obra comienza, a partir de este instante, a convertirse en una sucesión lógico-causal de acontecimientos que la sitúa en las coordenadas de la novela y el cine clásicos (Bordwell 1996, 159). El bloqueo creativo del poeta, que se evidencia ya en la primera aparición de su personaje en pantalla, es solucionado por el autor con la narrativización del poema/filme, con la disposición de su contenido en arreglo a los cánones novelescos tradicionales, lo cual provoca que en la historia haga aparición un personaje externo, el Cirujano, que funciona como detonante de la trama (McKee 2002, 223) y potencia los subsiguientes puntos de giro que irá adoptando la historia en las próximas secuencias.

Él, ante la visita del Cirujano, se alegra, es decir, el personaje del poeta en la obra "acepta» el viraje de la misma hacia la narrativa convencional y decide sin dudarlo formar parte de ella. Él quiere que se quede a dormir con ellos; Ella, por el contrario, se muestra reticente en todo momento a la inclusión del personaje extraño en su casa, en su mundo, en definitiva en su historia, y aduce la necesidad de escribir del poeta y la creación

3. Para más información acerca de la utilización de la voz como elemento lírico en el cine, puede verse el análisis de El espejo de Tarkovski en SEOANE 2015. 
en la que se halla inmerso como uno de los motivos fundamentales para la exclusión del Cirujano. El nuevo personaje es, además, un hombre de carácter intrigante y violento que, si bien empatiza con el poeta desde el inicio, adopta actitudes de indiferencia, rechazo e incluso de amenaza con la mujer del poeta.

Se forma, pues, el conflicto fundamental que sustentará el poema/filme hasta su conclusión y que constituye la razón de ser de Madre!: la libertad formal contra las normas constructivas del contenido, la vanguardia artística contra los cánones académicos, el cine puro contra el cine como vehículo transmisor de historias, la poesía contra la novela tradicional. La constante lucha entre el polo prosaico y el polo poético, si aplicamos una denominación clásica como la de Cohen (1977), irá construyendo el poema/filme y acercándolo a veces más hacia un extremo que hacia el otro, de modo que en ese vaivén se irá produciendo el avance de la historia; avance que no siempre seguirá normas lógico-causales, sino que irá progresivamente decantándose hacia el caos formal y narrativo, con la consiguiente destrucción del sentido racional que el espectador espera después de los dos primeros actos del filme.

\section{SEGUNDO ACTO: RUPTURA DE LA COHERENCIA NARRATIVA}

La aparición del Cirujano da comienzo al segundo acto de la obra, en la que las tensiones entre la poesía y la narrativa convencional afloran. Si bien es cierto que durante este nudo central del filme predomina la articulación lógico-causal de las sucesivas escenas, la poesía, latente, da siempre muestras de su presencia y se va haciendo notar cada vez con más intensidad gracias a las figuras vicarias de la mujer y de la propia casa, que es tratada por el poeta/director como un personaje más.

La mañana siguiente a la llegada del Cirujano, salen, los dos hombres, a dar un paseo por el bosque que no se introduce en la historia mientras la mujer se queda en la casa. Ante una narración que parece atenerse, al menos momentáneamente, a los cánones convencionales, se evoca la presencia subterránea de la poesía, a nivel visual y sonoro, de la siguiente forma: Ella se da cuenta de que en el sótano ocurre algo sobrenatural, o al menos de difícil explicación, pues escucha golpes en las paredes y sonidos que provienen de allí abajo; cuando desciende, observa que en el interior de la caldera existe una llama, un fuego oculto que sirve, a la vez, de elemento generador/destructor del mundo poético (como se sugirió ya a principio del filme con las imágenes ofrecidas, sin aparente sentido, pero que lo van adquiriendo paulatinamente) y de ítem que prepara al espectador 
para la tragedia, de objeto premonitorio del fatum clásico. Por otra parte, los golpes en las paredes y los sonidos extraños podrían relacionarse con el silencio del autor/director a nivel creativo, pues el personaje de Él, autor del poema y a la vez actante de la narración, está ahora más implicado en sus funciones narrativas convencionales de actante que en su labor creativa como autor del poema/filme. La voz poética, pues, que dota al poema de ritmo y que se había presentado de modo muy sugerente en la segunda escena, está silenciada, oprimida por la narración convencional, y se muestra de modo implícito a través de golpes, sonidos y ruidos que producen el estremecimiento de la casa y que solo Ella, la musa, es capaz de percibir.

Durante este mismo acto de la película se observa otro suceso que incide en el sentido global desde el que estoy enfocando mi análisis: el Cirujano ve el diamante que el poeta guarda en su estudio, y se siente fascinado por él; se acerca e intenta cogerlo, pero el poeta se lo impide bruscamente, no deja que lo toque y le explica que encontró ese objeto entre las cenizas del incendio de la casa, y que la propia casa ha sido reconstruida por su esposa. El corazón de la obra, del poema/filme, el diamante, es la cifra de la poesía y alrededor de él y de la musa se ha ido generando un nuevo mundo, que es en el que en esos momentos tiene lugar la historia que se narra.

La historia, ya ajustada a los cánones narrativos convencionales, se aposenta definitivamente en ellos ya que la trama exige un nuevo punto de giro y el poeta/director lo incluye en el poema/filme con la llegada de la mujer del Cirujano. En mitad de la noche Ella se despierta y observa cómo Él ayuda al Cirujano pues este está vomitando en el retrete: tiene cáncer. Este hecho podría observarse, desde nuestra óptica, como un debilitamiento de la narrativa tradicional ante la poesía, cada vez más presente en el poema/filme aunque el poeta/director se empeñe en inclinar la balanza hacia el polo narrativo. En ese momento, se produce la aparición de la esposa del Cirujano y con ella de un nuevo tema en el filme: el sexo. No le basta, al poeta/director, con la construcción lógico-causal de su relato, sino que introduce nuevas subtramas para aumentar el interés hacia la historia como suelen recomendar los manuales de guionistas (McKee 2002; Field 2001). El Cirujano y su mujer se besan apasionadamente mientras Él los observa emocionado y excitado (está contento con el nuevo rumbo que ha imprimido a la historia), pero Ella, como es natural, siente un profundo asco y rechaza tal situación fisiológicamente pues el nuevo giro narrativo con la intromisión de un tema muy manido y morboso en la obra va en contra de la esencia poética que se busca (y que la musa, según nuestro enfoque, representa); este malestar ante la situación se revela, además, como una indisposición física de su personaje. 
De aquí en adelante, el segundo acto comienza a perder fuerza narrativa pues las escenas se van sucediendo sin aparente sentido racional; los elementos sobrenaturales continúan irrumpiendo cada vez con más evidencia y lo poético termina por imponerse sobre la narración convencional que rige la historia. El pulso entre los dos polos, el prosaico y el poético, comienza a inclinarse a favor de este último.

Varios son los acontecimientos que lo van dejando claro. En primer lugar, la relación de las dos mujeres es de conflicto continuo, ya que el nuevo personaje representa la simpleza de las historias convencionales y la musa representa todo lo contrario. En una escena, por ejemplo, Ella pinta pero es interrumpida por la mujer del Cirujano cuando esta entra a ofrecerle una limonada "especial", causando este hecho cotidiano la parálisis del proceso creativo, la rehabilitación de la casa que implica la creación del poema/ filme. Además, en ese instante le pregunta, en relación a la casa: «¿Por qué reconstruirla y no comprar otra?», con todo lo que ello implica. Y luego en relación a su matrimonio: «¿Por qué no tienes hijos?», a lo que Ella responde que el poeta no quiere, dando lugar esta vez a la intromisión del melodrama en la historia. A continuación, ambas bajan a la lavandería mientras el poeta/director está paseando; van allí abajo a hacer algo cotidiano, pedestre, ordinario: lavar. La mujer del Cirujano se burla entonces de la ropa interior de Ella y se vuelve a introducir el tema del sexo; le desliza que, quizá, Él no la quiera y por eso no desea hijos. La musa, acongojada por esta violenta vulneración de su intimidad, se queda sola y mira el fuego de la caldera resplandecer a lo lejos, el fuego generador/destructor acompañado de todo el valor alegórico que se le ha ido otorgando a lo largo de la obra.

Es entonces cuando ocurre el suceso que provoca la irrupción de la poesía, rompiendo con los «intentos» del poeta/director de narrar una historia convencional: el Cirujano y su esposa intentan tocar el diamante y lo rompen. El poeta rechaza la vulgaridad del recurso y grita «isilencio!»; la palabra resuena en la casa desde todos los ángulos, como si hubiese devuelto su voz interna al poema. El poeta/director parece haber admitido su error, deja volar su imaginación desentendiéndose ya de la narración tradicional, y desembocamos así en el tercer acto.

\section{TERCER ACTO: IRRUPCIÓN DE LA POESÍA PURA}

Señala Pérez Bowie $(2008,23)$ que en las cinematografías que se asimilan más a la poesía que a la novela se priman la sensorialidad, la indefinición temporal y otro tipo de elementos ante la sucesión lógico-causal de los acontecimientos en la historia para construir el relato. Madre! alcanza 
su dimensión poética más extrema a partir de estos momentos en que se libera de las convenciones narrativas. Se imponen entonces la antinarratividad, la poesía, y la irracionalidad poemática se adueña del poema/filme tanto en el desenlace de la historia como en su construcción. El poeta, de hecho, tapia su estudio y asevera que "nunca van a entrar aquí de nuevo".

A partir de este momento, el caos, entendido como ruptura de los nexos lógico-causales del montaje en favor de otro tipo de asociaciones, se adueña del filme/poema. El montaje, con un ritmo "in crescendo", se apoya cada vez más en elementos que remiten a asociaciones características de la praxis poética y que tienen que ver con la sensorialidad: el tacto, el oído, la vista: la sangre, los sonidos, los colores. Asociaciones que se establecen a través de un montaje "poético", cuyo objetivo principal es el de transportar al espectador hacia experiencias puramente emocionales, no intelectuales (Tarkovski 2011, 128).

Por todo lo que se ha venido explicando, la búsqueda de un significado bíblico en la aparición repentina e inexplicable de los dos hijos del Cirujano y su esposa resulta estéril: no porque no exista, que sí y es evidente, sino porque no es relevante para el sentido del filme ${ }^{4}$. La brutal pelea entre ambos y el asesinato de uno de ellos dota al relato de una trascendencia formal, emotiva y plástica mucho más poderosa que la historia de resonancias bíblicas relacionadas con Caín y Abel. Estas últimas conexiones son las que buscaría, desde nuestro enfoque del filme, un poeta/ director bloqueado creativamente y adocenado en la mediocridad, y es lo que, como ya se señaló al principio, ha intentado encontrar y ha efectivamente constatado la crítica. Nada más lejos del sentido original de la obra: denunciar la mediocridad de esos mismos recursos y contraponerlos al vuelo poético, liberado y artísticamente sobresaliente que el filme/poema alcanza en su tercer acto, cuando se libera en definitiva de las ataduras narrativas convencionales en las que el bloqueo creativo del director/poeta se movía hasta ahora.

La siniestra escena de la rana, en la que Ella, al limpiar la sangre del hermano muerto, abre un túnel con una herramienta para llegar al corazón de la casa, establece un reflejo perfecto de lo que el asesinato significa en la historia: la sangre no desaparece y se filtra hasta el tuétano del poema/ filme. En ese momento, Ella, que se había quedado sola en la casa pues el resto de personajes habían partido al hospital, se encuentra al asesino deambulando por las habitaciones, y este le dice: «Te han dejado sola. ¿Lo

4. En el artículo ya citado de Mireia Mullor en Fotogramas (2017) se explica este suceso como una recreación sintética de la historia de Caín y Abel. 
entiendes?». Huelga explicar el sentido de esta frase, que es la clave del tercer acto.

Después de este momento el poeta llega, se ducha, se duerme y la pantalla corta a negro: el poema se suspende, la voz del autor/director se apaga y cuando se despierta de nuevo el caos reina en el relato, que de pura fragmentación y barroquismo se torna casi incomprensible. Se convoca un velatorio y empieza a llegar muchísima gente; la historia vira hacia la destrucción de la casa por parte de la turbamulta de personas y los intentos infructuosos de la mujer para salvarla: va, en cierto modo, destruyendo las "historias nuevas» a las que el poeta/autor quiere abrir el poema/filme al dejar entrar a todos esos nuevos figurantes en la narración. Ella le grita: "¿Crees que ellos te van a ayudar?" (a crear su obra), y le reprocha "no me quieres ni follar».

Es entonces cuando se acuestan juntos de forma casi animal, hay un fundido a blanco y una transición de los ruidos a la respiración pues la poesía ha germinado; después, lentamente se revela un amanecer silencioso, tranquilo, lleno de luz en el que se despiertan ambos en la cama, cubiertos por sábanas blancas. Ella le dice a él: «Estoy embarazada». La relación de la fertilidad con la inspiración poética es evidente, y más si se mantiene la visión que hemos venido construyendo de la historia. El polo poético ha vencido con la fecundación de la musa, y el poema está preparado para ser, para existir. Es a partir de este momento cuando el filme abandona definitivamente la narratividad tradicional y se convierte en una sucesión poética de escenas cuyo valor no reside en los nexos lógico-causales ni en la resolución coherente de la historia que han predominado hasta aquí. Él se encierra en su estudio a escribir, se suceden varios encadenados de los que se deduce una anisocronía ${ }^{5}$ (la habitación del bebé ya está lista), termina el poema, ella lo lee, llora y le responde: «Es bellísimo». El clímax del poema/filme se alcanza con un montaje in crescendo que va elevando el ruido, la intensidad emocional y que cierra la obra en una estructura perfecta de anillo» (Utrera 2007, 56).

El comienzo del fin es la llegada de la editora y, con ello, todo lo que rodea a la poesía pero no es poesía: lo extrapoético, el mercado, las ventas, los fans, la idolatría del escritor, todo lo que apaga y va en contra del arte y su sentido final: no solo hay que luchar contra la narratividad tradicional (con todos sus clichés y mediocridades, como se ha venido señalando), sino contra el mundo cotidiano. Celebran, pues, con una cena

5. Siguiendo la terminología genettiana (1989). 
que ha vendido todos los ejemplares de la obra el primer día y entonces comienzan a llegar, sin explicación aparente, los fans. El ego, el otro gran peligro para la poesía aparte de la mediocridad literaria en sí, se refleja en la frase que el poeta le dice a Ella: "Ellos han venido para verme a mí.

Mientras tanto, la mancha de sangre que había permanecido en la habitación del asesinato (ahora la del bebé) ha ido aumentando de tamaño. La mayoría de los planos se caracterizan por su marcada subjetividad: desde que se muestra un primerísimo primer plano de los ojos de la musa, la narración se nos presenta a menudo en ocularizaciones internas primarias y secundarias $^{6}$, ya que es su mirada aterrorizada y confusa el enfoque elegido por el poeta/director para mostrar el final de su obra. La musa intenta por todos los medios sobrevivir a la turbamulta de gente que comienza a entrar y destruir la casa (la obra) y que el poeta excusa diciendo que su casa (su obra) «es la casa de todos». El filme/poema termina alcanzando su clímax en una confusión temática y estilística absolutamente indescriptible: hay referencias a la religión, las drogas, las desigualdades sociales, la represión gubernamental o el terror, ya que en la casa se suceden manifestaciones, rituales, cargas policiales, bacanales... se escuchan gritos y protestas en distintos idiomas (en castellano, por ejemplo, «el pueblo unido jamás será vencido").

De pronto, la casa comienza a temblar como si un terremoto sacudiese espasmódicamente sus cimientos, en una clara hipálage visual pues Ella está teniendo contracciones; acto seguido se encierra en el estudio del poeta (significativo lugar) y da a luz. El montaje funde a blanco y se escuchan las palabras de la madre (Mother!): «Es un niño». Todo permanece en silencio hasta que Él abre la puerta, coge una cesta para el bebé y permite que los visitantes le traigan regalos; las resonancias bíblicas en este punto de la historia son muy claras. El matrimonio mantiene entonces una discusión, pues la madre pide: "Por favor, haz que se vayan", a lo que Él responde: "Quieren ver al niño, no quiero que se vayan, déjame coger al bebé», y Ella replica: «No», y Él: «Soy su padre», y finalmente Ella: «Soy su madre». Este tema de la relación paterno/materno filial establece un claro paralelismo entre el tema de la poesía esencialista, cuya clave reside en el mundo, en la inspiración, en la musa, o la pragmática, que presupone que es una creación artificial del poeta; además, llevándolo al terreno de la teoría fílmica, pueden encontrarse interesantísimas resonancias en la discusión

6. Siguiendo la terminología de CASETti y Di Chio (2010). 
entre Rohmer y Pasolini en Cine de poesía contra cine de prosa (1970) que trata Mirizio en este mismo número?.

La narración continúa y Él se sienta contemplando cómo Ella da el pecho al bebé. Poco a poco, amanece y el recién nacido sigue mamando. Ella le ruega otra vez: «Por favor, haz que se vayan». Él guarda silencio; se hace de noche, continúa mirándolos. El bebé se duerme y Ella se duerme. Y de pronto, se despierta por el ruido de unos aplausos: Él le había quitado el niño mientras dormía para enseñarlo a la multitud. Entonces empieza la adoración, la locura desatada en la que la gente, enajenada y en medio de un ritual, devora al bebé. Entonces la madre comienza a asesinar aleatoriamente a las personas que la rodean, pero la masa la lincha, con lo cual no solo se destruye al niño sino que se intenta destruir a la musa. "Lo has matado tú", le dice al poeta; "Necesitamos perdonarles", contesta él.

Ella, desesperada, va contra todo y todos y quema la casa desde abajo: extrae el aceite de la caldera (con lo que se cumple el fatum) y lo utiliza para prender fuego a todo con un mechero que previamente le había escondido al Cirujano: ellos dos son los primeros en arder. La casa explota junto con todo lo que la circunda: la obra se autodestruye, finalizando en una estructura de anillo perfecta. A ella le cae una lágrima y el montaje funde a blanco.

Tras el fundido Él la lleva, quemada, en brazos, y le dice: «Yo soy yo, tú eras mi hogar». Ella pregunta: «iA dónde me llevas?»; «Al principio», responde Él. La tiende en la cama: "Ahora debo crear de nuevo», le susurra; «no me queda nada que dar", contesta Ella. "Tu amor», dice Él. "Adelante», contesta Ella, "cógelo». Entonces, Él le arranca el corazón, y de sus cenizas sale el diamante del principio. Lo coloca en el pedestal, ríe y todo comienza de nuevo. La musa, ahora, es otra.

\section{FINAL}

La película Madre! constituye, pues, una versión visual del poema que el personaje de Él escribe en la historia, por lo que se trata, como señalé al principio, de una metamediación. Si recogemos todos los indicios que se han venido analizando, la construcción del propio poema/filme por parte del poeta/director es la que vertebra el relato, cuyas tensiones van fluyendo

7. Rohmer considera el cine como un mero transmisor de la poesía que efectivamente existe por sí misma en el mundo, y Pasolini considera la manipulación escritural propia del cine como un mecanismo de elaboración poética a partir de elementos de la realidad (PASOlini y RoHMer 1970). 
entre los polos prosaico y poético, siendo primero por el que se inclina al principio el creador para lograr romper una situación de bloqueo creativo; el polo poético y la libertad formal, asociados a la poesía y su lenguaje eminentemente antinarrativo, van abriéndose paso con el avance del filme hasta que la obra se convierte en el apogeo de la liberación que afecta a los dos niveles de la narración, el de la historia y el del relato, lo que hace de ella una creación estética perteneciente al ámbito poético y descontaminada de convencionalismos narrativos.

A nivel fílmico, estas tensiones se manifiestan en dos estratos: el primero, y que tiene que ver con lo paratextual, si seguimos la terminología de Genette (1989), es el de la producción, el casting y la explotación comercial de la película. Como se ha dicho, desde el director surge la intención de vender el filme como un producto convencional, de ahí la elección de los actores y la asimilación de la imagen publicitaria, carteles, tráileres, etcétera, a un género muy común: el del terror. Como se ha recogido en la introducción, tanto la crítica como el público se enfrentó a la película con un horizonte de expectativas ciertamente distinto a lo que la obra ofrece en sí misma, lo cual contribuye desde el mismo diseño de producción a crear el extrañamiento en el espectador.

La otra capa en la que se reproduce el conflicto es la textual, la de las propias formas fílmicas, cuyos polos narrativo y poético pueden situarse el primero en el modo de representación institucional definitorio del cine clásico, cuyos clichés se reproducen en el cine comercial contemporáneo, y el segundo en las vanguardias artísticas de principios de siglo Xx cuyo espíritu transgresor se recupera con el auge de los cines modernos de los años cincuenta y que continúan en determinados autores de cine contemporáneo como el propio Aronofsky.

De esta lucha, en ambos niveles, el paratextual y el textual, se extrae o se adivina un conflicto aún mayor, más general e importante y que constituye en verdad el verdadero tema del filme: el del cine como arte o el cine como producto de entretenimiento, y por ende el de cuál es la esencia y el sentido de las creaciones artísticas. Madre! es un poema fílmico, quizá uno de los más interesantes que se hayan escrito/rodado en los últimos tiempos, y sin duda la obra culmen de su director. Del mismo modo que para comprender la auténtica dimensión de un texto como La tierra baldía resulta infructuoso acercarse a él con el mismo enfoque con el que nos acercamos a la Divina comedia, a El cuervo o al Paraíso perdido, los esfuerzos de la crítica por desentrañar el significado de Madre! desde la narrativa convencional carecen y carecerán siempre de sentido: solo abordándola desde criterios estrictamente poéticos estaremos listos para comprender el auténtico significado de una obra como esta. 


\section{REFERENCIAS BIBLIOGRÁFICAS}

BAzIn, André. 1990. ¿Qué es el cine? Madrid: Rialp.

BORDWELl, David. 1996. La narración en el cine de ficción. Barcelona: Paidós.

CASETTI, Francesco y Federico Di CHIO. 2010. Cómo analizar un film. Barcelona: Paidós.

Cohen, Jean. 1977. Estructura del lenguaje poético. Madrid: Gredos.

Costa, Jordi. 2017. "El drama padre». El País. Web.

FIELD, Syd. 2001. El manual del guionista. Madrid: Plot.

GENETTE, Gérard. 1989. Figuras III. Barcelona: Lumen.

Koch, Tomasso. 2017. "Venecia pita a Aronofsky». El País. Web.

LLOPART, Salvador. 2017. "Mother!, de Darren Aronofsky, conmociona el festival de Venecia». La Vanguardia. Web.

LOUREDA, Carlos. 2017. "Mother: El film más ambicioso y arriesgado del festival. Darren Aronofsky prosigue su lectura punk de la Biblia (la versión terrestre del Arca de Noé)». Fotogramas. Web.

MARTínEZ, Luis. 2017. "Madre!: el prodigio que arde». El Mundo. Web.

McKeE, Robert. 2002. El guión. Madrid: Alba.

Mullor, Mireia. 2017. "Esto es lo que de verdad significa Madre! de Darren Aronofsky». Fotogramas. Web.

PARDO, Javier y Antonio GIL. 2018. «Intermedialidad: modelo para armar». En PARDO, Javier y Antonio GIL (eds.). Adaptación 2.0. Estudios comparados sobre intermedialidad, pp. 11-38. Francia: Orbis Tertius.

Pasolini, Pier Paolo y Éric RoHmer. 1970. Cine de poesía contra cine de prosa. Barcelona: Anagrama.

PÉREz BowIE, José Antonio. 2008. Leer el cine. La teoría literaria en la teoría cinematográfica. Salamanca: Ediciones Universidad de Salamanca.

Rodríguez Marchante, Oti. 2017. "Madre!: Bardem el escritor y sus demonios». $A B C$. Web.

SAlvá, Nando. 2017. "Aronofsky desata el caos en la Mostra». El Periódico. Web.

SEOANE Riveira, José. 2015. "Cine y autobiografía. Poesía e imagen en El espejo de Andrei Tarkovski». En Pérez Bowie, José Antonio y Pedro Javier Pardo (eds.). Transescrituras audiovisuales, pp. 229-249. Madrid: Sial Pigmalión.

TARKOvSKI, Andrei. 2011. Martirologio. Diarios 1970-1986. Salamanca: Sígueme.

Utrera MACíAs, Rafael. 2007. Literatura y cine. Adaptaciones I. Sevilla: Cuadernos de EIHCEROA.

YÁÑEZ, Manu. 2017. «Madre!». Fotogramas. Web. 